\title{
Pelatihan Pemanfaatan Mobile Aplikasi Edmodo Pada Guru Seni Budaya
}

\author{
Training of the Usage of Edmodo Mobile Application for \\ Cultural Arts Teachers \\ Heny Rohayani*, Agus Budiman, Trianti Nugraheni \\ Departemen Pendidikan Seni Tari, Fakultas Pendidikan Bahasa dan Seni, Universitas \\ Pendidikan Indonesia, Indonesia \\ *Corresponding author: E-mail: agusbudiman@upi.eduagus \\ Diterima: 08 Juni 2021; Direview: 31 Juli 2021; Disetujui: 14 Agustus 2021
}

\begin{abstract}
Abstrak
Tujuan penelitian ini ingin mengetahui hasil pelatihan pembelajaran daring pada guru-guru seni di PandeglangBanten melalui Mobile-Aplication Edmodo untuk dapat diterapkan dalam pembelajaan seni di sekolah. Penelitian kualitatif ini menggunakan sampel penelitian 31 peserta pelatihan dengan teknik purposive sampling. Data penelitian diperoleh dari hasil angket dan observasi. Hasil penelitian menunjukan bahwa mobile-aplication edomodo merupakan salah satu aplikasi yang bisa diakses melalui smartpone atau perangkat teknologi lainnya seperti laptop dan computer, dapat dijadikan sebagai forum atau sarana pembelajaran seni baik oleh guru maupun siswa melalui beberapa pilihan fitur yang dapat dijadikan sebagai akses media belajar mengajar oleh siswa dan guru. Hasil pelatihan ini mampu meningkatkan kemampuan pedagogik dan profesionalisme guru dalam melaksanakan pembelajaran seni berbasis teknologi. Kesimpulan penelitian ini adalah keterampilan guru menggunakan teknologi dalam pembelajaran seni di era industry 4.0 perlu ditingkatkan sebagai upaya mengadaptasi berbagai perkembangan teknologi dan informasi yang harus dimanfaatkan dalam pendidikan seni. Kata Kunci: Virtual Class; Teknologi; Mobile-Aplication Edomodo; Pembelajaran Daring; Pembelajaran Seni
\end{abstract}

\begin{abstract}
The purpose of this study was to determine the results of online learning training for art teachers in PandeglangBanten through Edmodo Mobile-Application to be applied in art learning in schools. This qualitative study used a research sample of 40 training participants with a purposive sampling technique. The research data were obtained from the results of questionnaires and observations. The results showed that the mobile-application edomodo is one of the applications that can be accessed via smartphones or other technological devices such as laptops and computers, which can be used as a forum or means of art learning by both teachers and students through several features that can be used as access to learning media taught by students and teachers. The results of this training are able to improve the pedagogical ability and professionalism of teachers in implementing technology-based art learning. The conclusion of this study is that the skills of teachers in using technology in art learning in the industrial era 4.0 need to be improved as an effort to adapt to various technological and information developments that must be utilized in art education.
\end{abstract}

Keywords: Virtual Class; Technology; Edomodo Mobile-Application; Online Learning; Art Learning

How to Cite: Rohayani, H., Budiman, A., \& Nugraheni, T. (2021). Pelatihan Pemanfaatan Mobile Aplikasi Edmodo Pada Guru Seni Budaya. Journal of Education, Humaniora and Social Sciences (JEHSS), 4 (2): 947-958.

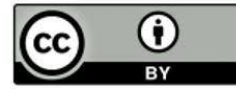




\section{PENDAHULUAN}

Kemajuan teknologi di era industry 4.0 adalah sesuatu yang tidak bisa kita hindari dalam kehidupan ini, karena kemajuan teknologi akan berjalan sesuai dengan kemajuan ilmu pengetahuan (Chea, Tan, \& Huan, 2019). Setiap inovasi diciptakan untuk memberikan manfaat positif bagi kehidupan manusia. Memberikan banyak kemudahan, serta sebagai cara baru dalam melakukan aktifitas manusia(Aghion, Bergeaud, Lequien, \& Melitz, 2018; Dube \& Gumbo, 2017; Hyland \& Soosay, 2008; Kaminski, 2011). Kehadiran teknologi yang terus berkembang saar ini terutama pada komputer dan internet sudah lama dimanfaatkan oleh negara-negara maju (Morris, 2014).

Sekarang ini rasanya sulit sekali mencari suatu masyarakat baik di perkotaan maupun perkotaan yang sama sekali tidak terpengaruh untuk menggunakan alat komunikasi handphone (Jacob \& Issac, 2008). Handphone sudah menjadi sebuah kebutuhan primer masyarakat sebagai alat komunikasi yang mampu menghubungkan seseorang tanpa terbatasi ruang dan waktu(Gordon, 2017; Han \& Shin, 2016; Roney, 2016). Perkembangan teknologi handphone saat ini beriringan secara langsung dengan kemajuan budaya internet atau budaya dgitalisasi (Fletcher, Everatt, Mackey, \& Fickel, 2020). Oleh karena, setiap perubahan product handphone dari berbagai pabrikan selalu menawarkan fasilitas browsing dan koneksi dengan internet yang secara bebas mampu mengakses berbagai informasi yang dibutuhkan setiap individu yang menggunakannya(Cutajar, 2019; Enright \& Gard, 2016; Jooston, Lee-McCarty, Harness, \& Paulus, 2020).

Memahami kondisi di atas, maka kita perlu menyikapi realitas kemajuan teknologi tersebut dalam berbagai aktivitas sehari-hari, termasuk dalam kegiatan pembelajaran di sekolah(Cutajar, 2019; Enright \& Gard, 2016; Grand-Clement, 2017; Kryukov \& Gorin, 2017). Seorang guru harus mampu memanfaatkan kecanggihan teknologi saat ini untuk dipergunakan dalam kegiatan belajar mengajar di sekolah agar kegiatan pembelajaran menjadi lebih menarik dan updaptif dengan berbagai perkebangan informasi yang dapat diperoleh dari akses internet secara online (Hendry, 2019; Phillips, 2016). Salah satu terobosan yang dapat dilakukan guru dan siswa untuk mewujudkan kegiatan pembelajaran berbasis e-learning adalah dengan memanfaatkan aplikasi mobile(Furió, Juan, Seguí, \& Vivó, 2015; Siahaan, 2020).

Edmodo adalah platform media sosial yang sering digambarkan sebagai Facebook untuk sekolah dan dapat berfungsi lebih banyak lagi sesuai dengan kebutuhan. Edmodo sebagai aplikasi berbasis cloud kolaborasi merupakan aplikasi yang cukup aman digunakan oleh guru dan siswa. Rismayanti (2012), Edmodo seperti alat bantu belajar lainnya, bisa menjadi hanya sebuah platform online untuk mendorong pembelajaran guru, atau dapat menjadi cara lebih kreatif untuk melibatkan para siswa dalam pembelajaran kolaboratif dan kognisi terdistribusi.

Penggunaan aplikasi Edmodo dalam pembelajaran dapat dikatakan sebagai suatu bentuk alternative inovasi dalam mengelola proses pembelajaran yang self regulated learning(Furió et al., 2015; Siahaan, 2020; Vania, Setiawan, \& Wijaya, 2018; Yagci, 2015). Self regulated learning menempatkan pentingnya seseorang untuk belajar disiplin mengatur dan mengendalikan diri sendiri, terutama bila menghadapi tugas-tugas yang sulit(Zimmerman, 1989; Zimmerman \& Martinez-Pons, 1988). Pada sisi lain self regulated learning menekankan pentingnya inisiatif(Boekaerts \& Corno, 2005; Winne \& Perry, 2000). Siswa yang memiliki inisiatif menunjukkan kemampuan untuk mempergunakan pemikirannya, perasaan-perasaannya, strategi dan tingkah lakunya yang ditunjukkan untuk mencapai tujuan (Zimmerman, 2002).

Sebuah survey yang dilakukan oleh APJII (Asosiasi Penyelenggara Jasa Internet Indonesia) menunjukkan dari 143,26 juta pengguna internet di Indonesia, 44,16\% diantara mengakses menggunakan mobile-phone, 39,28\% menggunakan mobile phone \& komputer, dan $4,49 \%$ hanya menggunakan komputer. 


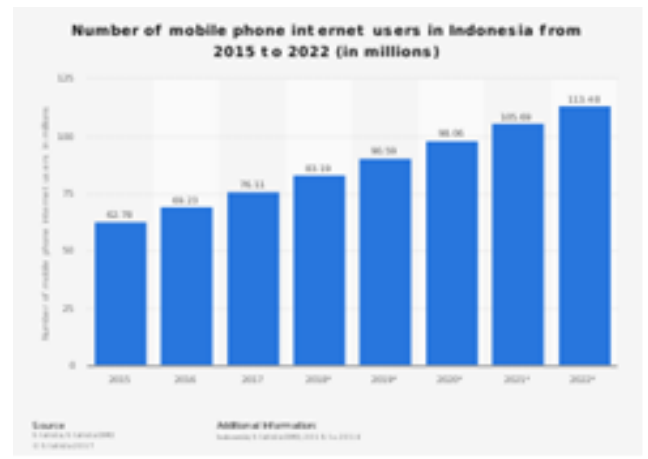

Gambar 1. Penetrasi Mobile Phone di Indonesia (https://apjii.or.id/survei)

Dimungkinkannya e-learning dijalankan melalui mobile teknologi diulas oleh beberapa peneliti, di antaranya; (Koohang, Riley, Smith, \& Schreurs, 2009) menyatakan bahwa elearning adalah salah satu jenis sistem pendidikan terbaru yang telah menarik perhatian para pendidik di dunia (Ehlers, 2009; Moore, Dickson-Deane, \& Galyen, 2011). E-learning adalah metode yang memungkinkan orang terutama siswa untuk mengambil kursus di rumah atau di manapun karena ia dapat mengakses internet, di antara platform lainnya seperti peer-to-peer, clienterver, dan layanan web(Mikul'a`s Huba, n.d.; Tîrziu \& Vrabie, 2015; Woodill, 2004).

Beberapa penelitian tentang penggunaan mobile teknologi dalam pembelajaran telah dilakukan, di antaranya: dalam penelitian (Fahri \& Samsudin, 2012) meneliti tentang penggunaan, teknologi seluler proses belajar mengajar di kelas. Dalam penelitiannya di temukan bahwa responden sangat menjawab menerima interaktivitas, aksesibilitas, dan kenyamanan dari sistem, tetapi mereka cukup frustrasi dengan sesekali gangguan karena masalah konektivitas internet. Akan tetapi, dalam hasil penelitiannya menunjukan bahwa secara keseluruhan, sistem pembelajaran mobile dapat digunakan sebagai yang murah tapi pembelajaran yang ampuh. (Heflin, Shewmaker, \& Nguyen, 2017) meneliti tentang mengevaluasi cara belajar siswa di tiga lingkungan belajar kolaboratif yang berbeda, dengan dan tanpa teknologi seluler, untuk menilai keterlibatan siswa, pemikiran kritis, dan sikap terhadap pembelajaran kolaboratif. (You, 2020) meneliti tentang pembelajaran tari dengan penggunaan tenologi Internet untuk mengetahui bagaimana siswa mempelajari 'Koreografi dan Dance 'melihat dampak pendidikan online pada formasi kompetensi mata pelajaran tertentu dan untuk mengidentifikasi kompetensi tersebut yang ditanamkan oleh program pelatihan online yang ideal. Namun, belum ada penelitian yang secara khusus memfokuskan upaya membangung pembelajaran seni berbasis virtual class melalui pembinaan dan pelatihan kepada guru-guru seni agar memiliki kemampuan keterampilan dalam merancang dan mengimplementasikan pembelajaran seni secara online melalui penggunaan aplikasi edmodo.

Dalam pengertian ini, pembelajaran berbasis web dan teknologi tampaknya mampu merangsang dan mendukung proses pembelajaran dan meningkatkan hasil pembelajaran (Wood et al., 2012). Siswa didorong untuk berpartisipasi dalam dialog aktif dengan siswa dan instruktur lain dan untuk berkolaborasi dengan orang lain yang tidak aktif untuk membangun pengetahuan dan menemukan prinsip untuk diri mereka sendiri (Lou, Shih, Diez, \& Tseng, 2011; Ritz \& Fan, 2015; Shih, 2011).

Tujuan penelitian ini adalah ingin memperoleh gambaran hasil pelatihan aplikasi edmodo kepada guru-guru seni budaya di kabupaten Pandeglang-Banten. Kegiatan penelitian ini dilakukan untuk membantu guru agar memiliki pengetahuan dan keterampilan sehingga mampu mengoptimalisasikan pembelajaran seni budaya melalui mobile application edmodo. Selain itu, kegiatan pengabdian kepada masyarakat ini adalah salah satu upaya untuk meningkatakan kompetensi pedagogi. Kompetensi pedagogi merupakan salah satu jenis kompetensi yang mutlak perlu dikuasai guru (Anggraeni, Yuliawati, \& PGMI, 2016; Budiman, Sabaria, \& Purnomo, 2020; Mulyasa, 2008).

Strategi pembelajaran dengan menggunakan mobile application edmodo diharapkan mampu meningkatkan minat, motivasi, kreativitas, produktivitas dan prestasi hasil belajar siswa బww $h$ http://mahesainstitute.web.id/ojs2/index.php/jehss œ1. mahesainstitut@gmail.com 949 
dalam pembelajaran seni budaya di sekolah. Untuk mewujudkan itu semua, kegiatan pelatihan ini dirancang secara terprogram melalui model pelatihan cara mengoprasionalkan mobile application edmodo melalui berbagai perangkat teknologi seperti handphone, komputer, dan laptop (Khodary, 2017; Saez, Lorraine, \& Miyata, 2013; Sumardi \& Muamaroh, 2020).

\section{METODE PENELITIAN}

Pendekatan penelitian yang digunakan dalam penelitian ini dilakukan secara kuantitatif. Untuk melihat adanya pengaruh hasil pelatihan aplikasi edmodo terhadap kemampuan guruguru seni budaya di Kabupaten Pandeglang Banteng. Teknik pemilihan sampel penelitian menggunakan teknik purposive sampling sehingga di dapat sampel penelitian 31 peserta pelatihan dengan kriteria peserta terdiri dari 12 Guru Seni Tari, 8 Guru Seni Musik, dan 11 Guru Seni Rupa. Data penelitian diperoleh dari hasil angket dan observasi saat kegiatan berlangsung.

Tabel 1.Peserta Pelatihan

\begin{tabular}{ll}
\hline Guru Seni Budaya & Jumlah \\
\hline Guru Seni Tari & 12 \\
Guru Seni Musik & 8 \\
Guru Seni Rupa & 11 \\
Total & 31 \\
\hline
\end{tabular}

Tahapan pelaksanaan pelatihan dilakukan melalui 3 tahapan kegiatan yaitu tahapan awal (tahapan persiapan), tahapan pelaksanaan, tahapan evaluasi program pelatihan (Karyati, Budiman, Rohayani, \& Sunaryo, 2020). Program ini memiliki maksud dan tujuan di antaranya memberikan gagasan dan gambaran terkait program pelatihan yang diimplementasikan pada guru-guru seni budaya di Kabupaten Pandeglang Banteng. Khususnya dalam meningkatkan kemampuan pedagogic guru menimplementasikan pembelajaran berbasis teknologi mobile. Implementasi dimulai dengan melakukan studi pustaka tentang pembelajaran jarak jauh. Dalam program pelatihan ini, langkah-langkah kegiatan pelatihan yang dikembangkan mengacu pada bentuk pengelolaan pelatihan menurut Sudjana dalam (Kamil, 2010), yang mengembangkan sepuluh langkah pengelolaan pelatihan (Karyati et al., 2020).

Analisis data dilakukan secara kuantitatif dalam melihat perbedaan rata-rata hasil pretes dan posttest melalui uji paired sampel t-test melalui program SPSS window 22.0.

\section{HASIL DAN PEMBAHASAN}

\section{Tahapan Persiapan Pelatihan}

Teknis pelatihan dimulai dari persiapan pelatihan, pelaksanaan pelatihan, evaluasi pelatihan, dan tindak lanjut. Pertama, persiapan yang dilakukan panitia beserta instruktur mencari informasi mengenai materi yang akan dilibatkan dalam program pelatihan. Alasan menggunakan edmodo ini adalah dari level kemudahan dalam pengelolaan kelas virtual dan aktifasinya, dapat diakses melalui media komputer dan handphone. Pada tahap ini, panitia mempersiapkan daftar hadir, media dan perangkat audio visual, ruangan, kelistrikan, modul materi, instrumen pre test dan posttest.

Tahapan ini sudah sesuai dengan langkah pengelolaan pelatihan dalam fungsi perencanaan menurut (Sudjana, 2007), yang terdiri dari, yaitu: a) identifikasi kebutuhan, sumber-sumber, dan kemungkinan hambatan yang akan dialami dalam pelatihan, b) perumusan tujuan pelatihan, c) penyusunan program pelatihan, d) penyusunan alat evaluasi, dan e) penyiapan pelatihan untuk pelatih.

Perencanaan sebagai proses untuk memilih dan menghubungkan fakta untuk dibuat menjadi suatu asumsi mengenai masa yang akan datang dengan merumuskan langkah kegiatan untuk mencapai hasil yang diinginkan (Barbazette, 2006; Caffarella \& Daffron, 2013; Cekada, 2010; Hasibuan \& Dantes, 2012).. Materi dalam Pelatihan Learning Management System www.edmodo.com.com ini ialah 
pengenalan pembelajaran jarak jauh (15 menit), pengenalan situs Edmodo (30 menit), dan praktek pembuatan akun Edmodo ( \pm 3 jam). Ke dua, pelaksanaan pelatihan yang dilaksanakan 27 Juli 2019 dari pukul 09.00 sampai 16.00 WIB di Gedung PGRI Kabupaten Pandeglang. Narasumber kegiatan adalah Purnomo, M.Pd. yang merupakan Dosen Teknologi dan Informasi Departemen Pendidikan Kemasyarakatan. DIhadiri 31 orang yang merupakan guru aktif seni budaya di Kabupaten Pandeglang. Mereka pun membawa laptop/notebook dan modem masing-masing.

Laptop/netbook dan modem ini sebagai media pembelajaran. Karena keterbatasan dana maka teknologi ini masing-masing guru bawa sendiri. Media adalah segala sesuatu yang dimanfaatkan dalam menyampaikan pesan sehingga dapat merangsang perhatian peserta pelatihan dalam proses pembelajaran agar dapat mencapai tujuan (Kusuma \& Subkhan, 2015; Muhson, 2010).

Strategi merupakan cara yang harus ditempuh untuk mencapai suatu tujuan, dengan adanya strategi maka proses pencapaian tujuan akan menjadi lebih terarah dan sesuai dengan yang diharapkan. Maka dari itu, untuk mencapai hal tersebut para trainer mempersiapkan diri dengan menerapkan variatif metode, terdiri dari demonstrasi, simulasi, fun game berbasis on-line, ceramah, tanya jawab dan praktek. Dengan menerapkan variatif metode tersebut, maka akan memberikan dampak yang signifikan terhadap penerimaan materi. Karena peserta adalah orang dewasa, maka trainer menekankan prinsip pembelajaran partisipatif, berbasis kepada masalah, mengungkap pengalaman peserta, dan dikaitkan dengan kasus pembelajaran yang ditemui sehari-hari.

Ke tiga, evaluasi diklat yang akan dilaksanakan dalam pelatihan pembuatan LMS ini ialah evaluasi formatif dan evaluasi sumatif. Dalam evaluasi pembelajaran, kami melakukan pengujian pre-test di awal, ketika proses pelatihan berlangsung dan post-test di akhir pelatihan sehingga kemampuan masingmasing peserta dapat diketahui.

Hasil evaluasi yang diperoleh menunjukan bahwa proses pelatihan berjalan sesuai dengan rencana dan tujuan yang telah ditetapkan, antusiasme para peserta pelatihan cukup baik dan pelaksanaan pembelajaran berjalan dengan lancar, kebanyakan peserta mampu mengikuti dan memahami proses pembelajaran dan mampu menyerap materi dengan baik sehingga bisa menjalankan aplikasi sesuai dengan arahan.

Hasil pelatihan dapat diamati dari data pretest dan postest yang menunjukkan adanya perbedaan nilai pretest dengan nilai post-test. Berikut hasilnya ditampilkan dalam table di bawah ini.

Tabel 2. Nilai Pretest dan Postest

\begin{tabular}{|c|c|c|c|}
\hline No & Nama & Pre Test & Pos Test \\
\hline 1 & Muhammad wildan & 60 & 90 \\
\hline 2 & Annisa & 60 & 85 \\
\hline 3 & Lia normasari & 60 & 84 \\
\hline 4 & Samsul aripin & 65 & 90 \\
\hline 5 & Hendri setiawan & 40 & 81 \\
\hline 6 & Yeni puspita sari & 55 & 92 \\
\hline 7 & Nana sumarna & 65 & 90 \\
\hline 8 & Dian puspita sari & 75 & 85 \\
\hline 9 & Eka agusdini & 60 & 90 \\
\hline 10 & Arni kharunia & 65 & 80 \\
\hline 11 & Iwan gunawan, & 60 & 85 \\
\hline 12 & Bai suirot & 70 & 90 \\
\hline 13 & Aep saepudin & 65 & 90 \\
\hline 14 & Yuniati & 40 & 80 \\
\hline 15 & Septia nurhalimah & 60 & 80 \\
\hline 16 & Rini apriani & 40 & 85 \\
\hline 17 & Sona maulana & 55 & 90 \\
\hline 18 & Agus salamullah & 60 & 85 \\
\hline 19 & Kiki kristiani & 65 & 90 \\
\hline 20 & Wiwin widiati & 70 & 90 \\
\hline 21 & Novialimar arifin & 55 & 90 \\
\hline 22 & Fian agnitia & 65 & 85 \\
\hline 23 & Kartini & 75 & 85 \\
\hline 24 & Ibnu hasan & 60 & 85 \\
\hline 25 & Elah harmilah & 65 & 90 \\
\hline ute. & veb.id/ojs2/index. & & ahesainst \\
\hline
\end{tabular}




\begin{tabular}{llll}
26 & Dadan johari & 60 & 90 \\
27 & Hilma afifah & 70 & 85 \\
28 & Regi prayoga & 65 & 80 \\
29 & Siti magelung sari & 60 & 90 \\
30 & Mokhamad syukron T & 65 & 85 \\
31 & Ratu lianas bilqis & 65 & 85 \\
\hline & Total & $\mathbf{1 8 9 5}$ & $\mathbf{2 6 8 2}$ \\
& $\mathbf{6 1 , 1 2}$ & $\mathbf{8 6 , 5 1}$ \\
\hline
\end{tabular}

Peningkatan pretest dan postest sebesar $4,7 \%$, menunjukan peningkatan yang cukup. Analisis kekuatan dalam pelatihan ini ialah bahwa para peserta pelatihan dapat berpartisipasi dalam program pelatihan secara professional, berdiskusi, melakukan tanya jawab dengan tertib. Hambatan yang diperoleh dari pelatihan ini adalah jaringan internet dari provider tertentu, sehingga kesulitan untuk mengakses situs e-learning. Problem lainnya, tidak semua peserta pelatihan yang terlibat dalam pelatihan memiliki kemampuan dasar yang sama dalam mengoperasikan teknologi. Oleh karena, dalam pelatihan ini peserta dituntut untuk dapat mempraktekkan secara langsung materi pelatihan penggunaan aplikasi edmodo melalui perangkat laptop yang dimilikinya masing-masing.

\section{Simulasi Praktek Menggunakan Aplikasi Edmodo}

Terakhir, kegiatan yang akan dilaksanakan sebagai tindak lanjut dari pelatihan adalah peserta dapat mempraktekkan seluruh materi yang diberikan sehingga peserta memiliki kemampuan tambahan untuk menunjang kredibilitas sesuai dengan pekerjaannya sebagai pendidik. Harapan lainnya adalah dilakukan pelatihan sejenis dengan sasaran siswa pada sekolah tersebut, sehingga terjadi sinergitas antara pendidik dan peserta didik dalam mengoperasionalkan situs www.edmodo.com untuk proses pembelajaran.

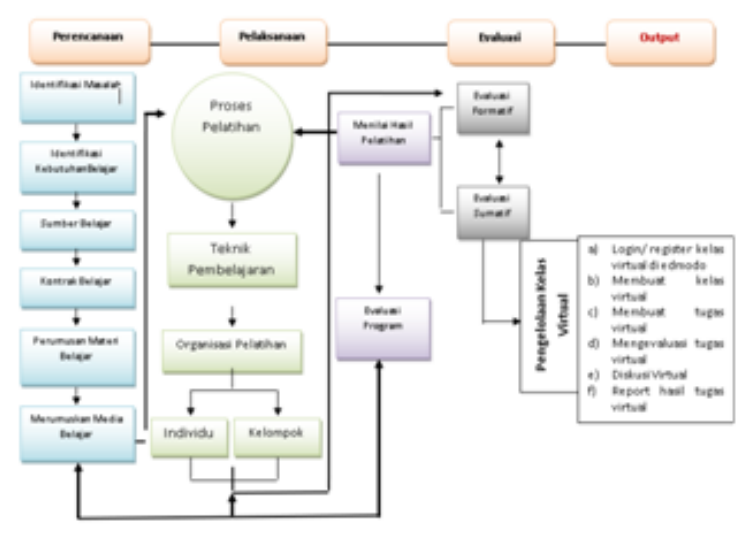

Gambar 2. Model yang diterapkan dalam program pelatihan

\section{Hasil Kepuasan Pelatihan}

Hasil kepuasan pelatihan dinilai dari penilaian kegiatan dan penilaian materi yang disampaikan. Hasil kepuasan terhadap kegiatan Pelatihan Edmodo tergambar dalam grafik di bawah ini. 


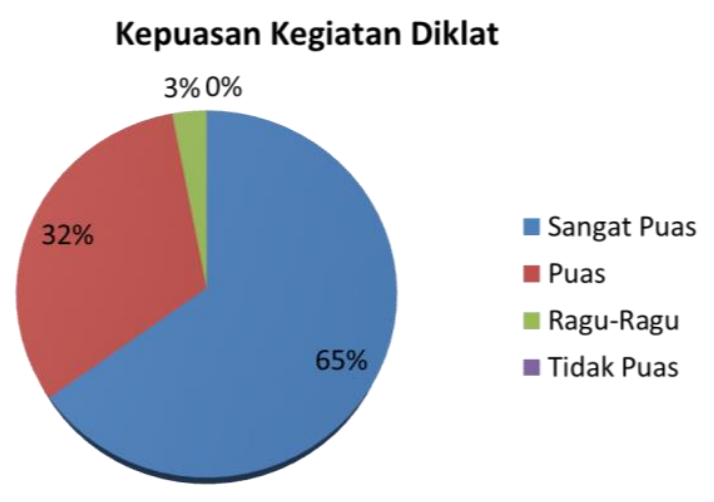

Grafik 1. Kondisi Kepuasan Peserta Diklat mengenai Kegiatan Diklat

Dapat diketahui dari grafik di atas bahwa 20 orang peserta pelatihan menyatakan sangat puas, 10 orang menyatakan puas, 1 orang menyatakan ragu-ragu. Semua peserta pada umumnya menginginkan waktu yang lebih panjang untuk satu kali pertemuannya. Peserta pelatihan merasa waktu pelatihan sangat kurang karena tidak langsung membuat para peserta pelatihan langsung mahir dalam mengaplikasikan situs www.edmodo.com tersebut.

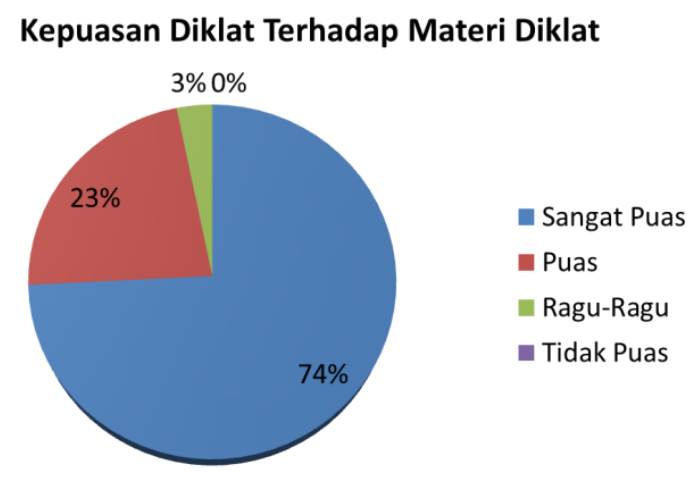

Grafik 2. Kondisi Kepuasan Peserta Diklat terhadap Materi Diklat

Dapat diketahui dari grafik di atas bahwa 23 orang peserta mengatakan sangat puas dengan materi yang disajikan, 7 orang mengatakan puas, dan 1 orang mengatakan ragu-ragu dengan materi yang disajikan. Hampir keseluruhan peserta bisa memahami dan mengikuti intruksi dari pemateri, hanya waktu dan kondisi internal para peserta yang kurang mendukung. Terutama berkaitan dengan fasilitas jaringan internet yang dibutuhkan, masih mengalami kesulitan.

\section{Analisis Hasil Pelatihan}

Perkembangan teknologi memberikan dampak besar terhadap proses pendidikan seni di sekolah sebagai bentuk inovasi pembelajaran yang dikembangkan guru dalam pembelajarannya (Pangestika \& Yanuartuti, n.d.). Kondisi ini dipengaruhi juga semakin modern dan canggihnya perkembangan era Era digital yang memberikan berbagai kemudahan kepada manusia untuk mengirim dan menerima berbagai informasi dan ilmu pengetahuan dari literasi digital yang semakin canggih(Heldisari, n.d.; Rumapea, n.d.).

Kemajuan teknolgi dalam era industry 4.0 (Coşkun, Kayıkcl, \& Gençay, 2019) harus direspon dengan positif dan cepat oleh guru seni budaya sebagai upaya adaptasi perkembanan jaman dan ilmu pengetahuan di abad modern dan canggih saat ini. Ketergantungan manusia dalam menggunakan media teknologi di era 4.0 tidak dapat dihindari lagi sebagai bentuk konsekuensi perkembangan peradaban IPTEK yang sudah tidak dapat dibendung lagi saat ini (Ehlers, 2009). Kecenderungan manusia beralih dari teknologi belajar konvesional ke teknologi 象 $\mathrm{http} / / /$ mahesainstitute.web.id/ojs2/index.php/jehss

ㄴ.1mahesainstitut@gmail.com 
belajar modern menuntut adanya keterampilan memadai dari guru seni untuk meningkatkan keahliannya dalam memanfaatkan teknologi dalam pembelajaran (Li, Zhou, \& Teo, 2018).

Pembelajaran seni di sekolah merupakan salah satu pembelajaran yang memiliki karakeristik khas yang di dalamnya terdapat kegiatan belajar secara teoritik, praktik dan apresiatif (Rosala \& Budiman, 2020). Ke tiga bentuk cara kegiatan belajar seni di sekolah tersebut perlu diadaptasikan dalam sebuah pembelajaran seni berbasis teknologi(Chung, 2018). Kondisi ini diharuskan pula untuk dilakukan seiring dengan kondisi pandemic corona COVID 19 yang menuntut peran guru agar memiliki keahlian yang cukup dalam mewujudkan suatu pembelajaran seni berbasis daring (Adnan \& Anwar, 2020; Assunção Flores \& Gago, 2020; Crick, Knight, Watermeyer, \& Goodall, 2020; Kraehe, 2020). Mode pembelajaran daring berbasis aplikasi edmodo ini sebagai salah satu alternative model pembelajaran daring (Gómez, Magreñán, \& Orcos, 2015; Hankins, 2015; Munir \& IT, 2009; Sumardi \& Muamaroh, 2020; Thongmak, 2013; Zamfiroiu \& Sbora, 2014) yang dimanfaatkan guru dalam kegiatan pembelajaran seni budaya.

Hasil program pelatihan yang telah dilaksanakan memiliki berbagai dukungan dan hambatan. Keduanya disajikan dalam gambar analisis SWOT di bawah ini.

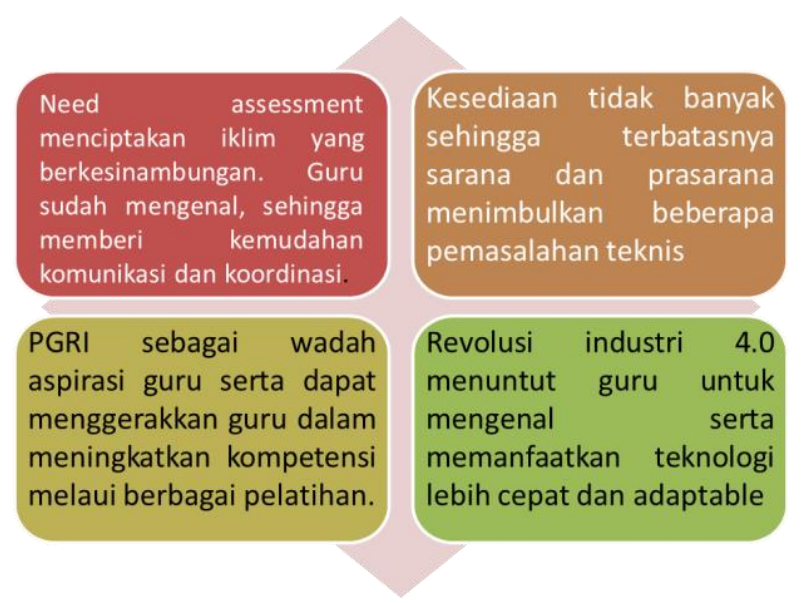

Gambar 3. Analisis SWOT Program Pelatihan

Table 3. Paired Samples Correlations

\begin{tabular}{|c|c|c|c|}
\hline & $\mathrm{N}$ & Correlation & Sig. \\
\hline Pair 1 & $\begin{array}{l}\text { Pretest \& } \\
\text { Posttest }\end{array}$ & .224 & .226 \\
\hline
\end{tabular}

Berdasarkan data output analisis di atas, dapat dianalisis bahwa nilai sig. 0.226 $>0,05$ nilai taraf normal. Hasil ini menunjukan tidak adanya korelasi antara hasil pretest dengan postest terhadap kemampuan para guru dalam menggunakan aplikasi edmodo hasil dari kegiatan pelatihan.

Table 4.Paired Samples Test

\begin{tabular}{rlll}
\hline \multicolumn{1}{c}{$\mathrm{t}$} & $\mathrm{df}$ & \multicolumn{1}{c}{ Sig. (2-tailed) } \\
\hline Pair 1 & $\begin{array}{l}\text { Pretest } \\
\text { Posttest }\end{array}{ }^{-}{ }^{-16.427}$ & 30 & .0oo \\
\hline
\end{tabular}

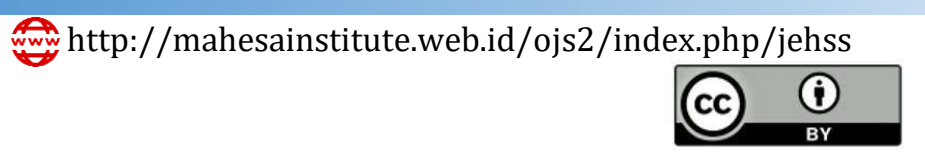


Berdasarkan data output analisis di atas, dapat dianalisis bahwa nilai sig. $0.000>0,05$ nilai taraf normal. Hasil ini menunjukan tidak adanya perbedaan rata-rata hasil pretest dengan postest terhadap kemampuan para guru dalam menggunakan aplikasi edmodo hasil dari kegiatan pelatihan.

\section{SIMPULAN}

Perkembangan teknologi handphone saat ini beriringan secara langsung dengan kemajuan budaya internet atau budaya dgitalisasi. Teknologi yang berkembang sangat cepat menjadi tuntutan bagi setiap orang untuk dapat mengimbanginya. Tak terkecuali guru sebagai salah satu sumber belajar. Guru dapat memanfaatkan teknologi internet sebagai media belajar. Pelaksanaan pelatihan ini membantu guru agar memiliki pengetahuan dan keterampilan sehingga mampu mengoptimalisasikan pembelajaran seni budaya melalui mobile application edmodo. Hasil akhir menunjukkan peningkatan nilai test peserta pelatihan. Selain itu, peserta pelatihan pun merasa puas dengan terselenggaranya pelatihan. Diharapkan ke depannya, pelatihan berbasis IT ini dapat bekesinambungan. Pelatihan seperti ini dapat menggerakkan guru untuk memanfaatkan teknologi dalam pembelajaran.Simpulan hendaknya merupakan jawaban atas pertanyaan penelitian, dan diungkapkan bukan dalam kalimat statistik. Ditulis sepanjang satu paragraf dalam bentuk esai, tidak dalam bentuk numerical. Manuskrip ditulis dengan kerapatan baris 1 spasi, huruf Cambria 12

\section{UCAPAN TERIMAKASIH}

Ucapan terima kasih ini Kami sampaikan kepada MGMP Seni Budaya Pandeglang Banteng, dan LPPM UPI yang telah memberikan dana untuk melakukan kegiatan penelitian ini.

\section{DAFTAR PUSTAKA}

01-sistem-sertifikasi-nasional-rev1_upgrading-02-nov-2018waktu-training1. (n.d.).

Adnan, M., \& Anwar, K. (2020). Online Learning amid the COVID-19 Pandemic: Students' Perspectives. Online Submission, 2(1), 45-51.

Aghion, P., Bergeaud, A., Lequien, M., \& Melitz, M. J. (2018). The impact of exports on innovation: Theory and evidence.

Anggraeni, M., Yuliawati, F., \& PGMI, F. (2016). Pengaruh persepsi peserta didik tentang kompetensi pedagogig pendidik terhadap motivasi belajar IPA di MI Muhammadiyah Taskombang Bidayah: Jurnal pendidikan guru Madrasah ibtidaiyah, Vol 8no 1. ISSN 2085, 34, 27-38.

Assunção Flores, M., \& Gago, M. (2020). Teacher education in times of COVID-19 pandemic in Portugal: national, institutional and pedagogical responses. Journal of Education for Teaching, 1-10.

Barbazette, J. (2006). Training needs assessment: Methods, tools, and techniques. John Wiley \& Sons.

Boekaerts, M., \& Corno, L. (2005). Self-regulation in the classroom: A perspective on assessment and intervention. Applied Psychology, 54(2), 199-231.

Budiman, A., Sabaria, R., \& Purnomo, P. (2020). Model Pelatihan Tari: Penguatan Kompetensi Pedagogik \& Profesionalisme Guru. Panggung, 30(4).

Caffarella, R. S., \& Daffron, S. R. (2013). Planning programs for adult learners: A practical guide. John Wiley \& Sons.

Cekada, T. L. (2010). Training needs assessment: Understanding what employees need to know. Professional Safety, 55(03), 28-33.

Chea, C. C., Tan, J., \& Huan, J. (2019). Higher Education 4.0: The Possibilities and Challenges. Journal of Social Sciences and Humanities, 5(2), 81-85. Retrieved from http://www.aiscience.org/journal/jssh

Chung, S. K. (2018). Art Education Technology: Digital Storytelling. Art Education, 60(2), 17-22. https://doi.org/10.1080/00043125.2007.11651632

Coşkun, S., Kayıkcı, Y., \& Gençay, E. (2019). Adapting Engineering Education to Industry 4.0 Vision. Technologies, 7(1), 10. https://doi.org/10.3390/technologies7010010

Crick, T., Knight, C., Watermeyer, R., \& Goodall, J. (2020). The Impact of COVID-19 and "Emergency Remote Teaching" on the UK Computer Science Education Community. United Kingdom \& Ireland Computing Education Research Conference., 31-37.

Cutajar, M. (2019). Teaching using digital technologies: Transmission or participation? Education Sciences, 9(3). https://doi.org/10.3390/educsci9030226 
Dube, C., \& Gumbo, V. (2017). Diffusion of innovation and the technology adoption curve: Where are we? The Zimbabwean experience. Business and Management Studies, 3(3), 34-52.

Ehlers, U. D. (2009). Web 2.0 - e-learning 2.0 - quality 2.0? Quality for new learning cultures. Quality Assurance in Education, 17(3), 296-314. https://doi.org/10.1108/09684880910970687

Enright, E., \& Gard, M. (2016). Media, digital technology and learning in sport: a critical response to Hodkinson, Biesta and James. Physical Education and Sport Pedagogy, 21(1), 40-54. https://doi.org/10.1080/17408989.2015.1043258

Fahri, H., \& Samsudin, K. (2012). Mobile Learning Environment System (MLES): The Case of Android-based Learning Application on Undergraduates' Learning. International Journal of Advanced Computer Science and Applications, 3(3), 1-5. https://doi.org/10.14569/ijacsa.2012.030311

Fletcher, J., Everatt, J., Mackey, J., \& Fickel, L. H. (2020). Digital Technologies and Innovative Learning Environments in Schooling: A New Zealand Experience. New Zealand Journal of Educational Studies, 55(1), 91-112. https://doi.org/10.1007/s40841-020-00156-2

Furió, D., Juan, M., Seguí, I., \& Vivó, R. (2015). Mobile learning vs. traditional classroom lessons: a comparative study. Journal of Computer Assisted Learning, 31(3), 189-201.

Gómez, A., Magreñán, A. A., \& Orcos, L. (2015). UX of Social Network Edmodo in Undergraduate Engineering Students. International Journal of Interactive Multimedia and Artificial Intelligence, 3(4), 31. https://doi.org/10.9781/ijimai.2015.346

Gordon, A. (2017). Social media marketing strategies in nonprofit professional membership organizations.

Grand-Clement, S. (2017). Digital Learning: Education and Skills in the Digital Age. RAND Europe.

Han, I., \& Shin, W. S. (2016). The use of a mobile learning management system and academic achievement of online students. Computers \& Education, 102, 79-89.

Hankins, S. N. (2015). The effects of Edmodo on student achievement in middle school. St. Thomas University Miami Gardens, Florida.

Hasibuan, Z. A., \& Dantes, G. R. (2012). Priority of key success factors (KSFS) on enterprise resource planning (ERP) system implementation life cycle. Journal of Enterprise Resource Planning Studies, 2012, 1.

Heflin, H., Shewmaker, J., \& Nguyen, J. (2017). Impact of mobile technology on student attitudes, engagement, and learning. Computers \& Education, 107, 91-99.

Heldisari, H. P. (n.d.). Musical Ability and Interpersonal Intelligence in The Late Childhood Period. Gondang: Jurnal Seni Dan Budaya, 4(2), 185-192.

Hendry, P. (2019). What is the Impact of Digital Technology on Young Students?

Hyland, P., \& Soosay, C. (2008). Innovation, technology and knowledge management. In Operations Management: An Integrated Approach. https://doi.org/10.1017/CB09781139150002.009

İnel, D., \& Balım, A. G. (2013). Concept cartoons assisted problem based learning method in science and technology teaching and students' views. Procedia-Social and Behavioral Sciences, 93, 376-380.

Jacob, S. M., \& Issac, B. (2008). Mobile Technologies and its Impact - An Analysis in Higher Education Context. International Journal of Interactive Mobile Technologies, 2(1), 10-18.

Jooston, T. (University of W.-M., Lee-McCarty, K. (Online L. C., Harness, Li. (Alverno C., \& Paulus, R. (National R. C. for D. E. and T. A. (2020). Digital Learning Innovation Trends. 33.

Kamil, M. (2010). Model pendidikan dan pelatihan (konsep dan aplikasi). Bandung: Alfabeta.

Kaminski, J. (2011). Diffusion of innovation theory. Canadian Journal of Nursing Informatics, 6(2), 1-6.

Karyati, D., Budiman, A., Rohayani, H., \& Sunaryo, A. (2020). Model Home Industri Seni : Studi Hasil Pelatihan Pembuatan Busana Tari Dalam Membantu Kemandirian Ekonomi Keluarga Model Home Art Industry: A Study on the Results of Training in Making Dance Clothing in Helping Family Economic Independence. 3(2), 682-692.

Khodary, M. M. (2017). Edmodo Use to Develop Saudi EFL Students' Self-Directed Learning. English Language Teaching, 10(2), 123-135.

Koohang, A., Riley, L., Smith, T., \& Schreurs, J. (2009). E-learning and constructivism: From theory to application. Interdisciplinary Journal of E-Learning and Learning Objects, 5(1), 91-109.

Kraehe, A. M. (2020). Dreading, Pivoting, and Arting: The Future of Art Curriculum in a Post-Pandemic World. Taylor \& Francis.

Kryukov, V., \& Gorin, A. (2017). Digital technologies as education innovation at universities. Australian Educational Computing, 32(1). 
Kusuma, Z. L., \& Subkhan, S. (2015). Pengaruh Motivasi Belajar dan Kedisiplinan Belajar terhadap Prestasi Belajar Mata Pelajaran Akuntansi Siswa Kelas XI IPS SMA N 3 Pati Tahun Pelajaran 2013/2014. Economic Education Analysis Journal, 4(1).

Li, Z., Zhou, M., \& Teo, T. (2018). Mobile technology in dance education: a case study of three Canadian high school dance programs. Research in Dance Education, 19(2), 183-196. https://doi.org/10.1080/14647893.2017.1370449

Lou, S.-J., Shih, R.-C., Diez, C. R., \& Tseng, K.-H. (2011). The impact of problem-based learning strategies on STEM knowledge integration and attitudes: an exploratory study among female Taiwanese senior high school students. International Journal of Technology and Design Education, 21(2), 195-215.

Mikul'a`s Huba, `Stefan Koz'ak. (n.d.). From E-learning to Industry 4 . 0.

Moore, J. L., Dickson-Deane, C., \& Galyen, K. (2011). E-Learning, online learning, and distance learning environments: Are they the same? Internet and Higher Education, 14(2), 129-135. https://doi.org/10.1016/j.iheduc.2010.10.001

Morris, N. P. (2014). How digital technologies, blended learning and MOOCs will impact the future of higher education. Proceedings of the International Conference E-Learning 2014 - Part of the Multi Conference on Computer Science and Information Systems, MCCSIS 2014, 401-404.

Muhson, A. (2010). Pengembangan media pembelajaran berbasis teknologi informasi. Jurnal Pendidikan Akuntansi Indonesia, 8(2).

Mulyasa, E. (2008). Menjadi Guru Profesional Menciptakan Pembelajaran.

Munir, D., \& IT, M. (2009). Pembelajaran jarak jauh berbasis teknologi informasi dan komunikasi. Bandung: Alfabeta.

Pangestika, F. Y., \& Yanuartuti, S. (n.d.). Pembelajaran Mandiri Seni Tari Melalui Konten Youtube sebagai Inovasi Pembelajaran Masa Kini. Gondang: Jurnal Seni Dan Budaya, 4(2), 144-151.

Phillips, M. (2016). Digital Technology, Schools and Teachers' Workplace Learning. In Digital Technology, Schools and Teachers' Workplace Learning. https://doi.org/10.1057/978-1-137-52462-1

Ritz, J. M., \& Fan, S.-C. (2015). STEM and technology education: International state-of-the-art. International Journal of Technology and Design Education, 25(4), 429-451.

Roney, L. N. (2016). Technology Use, Technological Self-Efficacy and General Self-Efficacy Among Undergradute Nursing Faculty.

Rosala, D., \& Budiman, A. (2020). Local Wisdom-based Dance Learning: Teaching Characters to Children through Movements. 7(3), 304-326. https://doi.org/10.17509/mimbar-sd.v7i3.28185

Rumapea, M. E. M. (n.d.). Tantangan Pembelajaran Musik Pada Era Digital. Gondang: Jurnal Seni Dan Budaya, 3(2), 101-110.

Saez, J., Lorraine, J., \& Miyata, Y. (2013). Using Edmodo in international collaborative projects in primary education. Edutec. Revista Electronica de Tecnología Educativa, (43), 1-17.

Shih, R.-C. (2011). Can Web 2.0 technology assist college students in learning English writing? Integrating Facebook and peer assessment with blended learning. Australasian Journal of Educational Technology, 27(5).

Siahaan, E. B. (2020). Students' Perception of Edmodo use as a Learning Tool. JET (Journal of English Teaching), 6(February), 12-23. https://doi.org/10.33541/jet.v6i1.1061

Sudjana, D. (2007). Sistem dan manajemen pelatihan teori dan aplikasi. Bandung: Falah Production.

Sumardi, S., \& Muamaroh, M. (2020). Edmodo impacts: Mediating digital class and assessment in english $\begin{array}{llll}\text { language teaching. } & \text { Cakrawala } & \text { Pendidikan, } & 319\end{array}$ https://doi.org/10.21831/cp.v39i2.30065

Thongmak, M. (2013). Social Network System in Classroom: Antecedents of Edmodo (c) Adoption. Journal of E-Learning and Higher Education, 2013, 1-15. https://doi.org/10.5171/2013.657749

Tîrziu, A.-M., \& Vrabie, C. (2015). Education 2.0: E-Learning Methods. Procedia - Social and Behavioral Sciences, 186, 376-380. https://doi.org/10.1016/j.sbspro.2015.04.213

Vania, P. F., Setiawan, W., \& Wijaya, A. F. C. (2018). Edmodo as Web-Based Learning to Improve Student's Cognitive and Motivation in Learning Thermal Physics. Journal of Science Learning, 1(3), 110. https://doi.org/10.17509/jsl.v1i3.11796

Winne, P. H., \& Perry, N. E. (2000). Measuring self-regulated learning. In Handbook of self-regulation (pp. 531-566). Elsevier.

Wood, E., Zivcakova, L., Gentile, P., Archer, K., De Pasquale, D., \& Nosko, A. (2012). Examining the impact of off-task multi-tasking with technology on real-time classroom learning. Computers \& Education, 58(1), 365-374.

Woodill, G. (2004). Where is the learning in e-learning?: A critical analysis of the elearning industry. Operitel Corporation Whitepaper. Retrieved from 
http://scholar.google.com/scholar?hl=en\&btnG=Search\&q=intitle:Where+is+the+Learning+in+Elearning+?+a+critical+analysis+of+the+e-learning+industry\#0

Yagci, T. (2015). Blended Learning via Mobile Social Media \& Implementation of “EDMODO” in Reading Classes. Advances in Language and Literary Studies, 6(4). https://doi.org/10.7575/aiac.alls.v.6n.4p.41

You, Y. (2020). Online technologies in dance education (China and worldwide experience). Research in Dance Education, 00(00), 1-17. https://doi.org/10.1080/14647893.2020.1832979

Zamfiroiu, A., \& Sbora, C. (2014). Statistical analysis of the behavior for mobile E-learning. Procedia Economics and Finance, 10, 237-243.

Zimmerman, B. J. (1989). A social cognitive view of self-regulated academic learning. Journal of Educational Psychology, 81(3), 329.

Zimmerman, B. J. (2002). Becoming a self-regulated learner: An overview. Theory into Practice, 41(2), 6470.

Zimmerman, B. J., \& Martinez-Pons, M. (1988). Construct validation of a strategy model of student selfregulated learning. Journal of Educational Psychology, 80(3), 284. 